\title{
Pentoxifylline: An Immunomodulatory Drug for the Treatment of COVID-19
}

\author{
Hiren A. Dhameliya $\mathbb{D}^{D}$, Vasudev R. Thakkar $\mathbb{D}^{\text {, }}$, Gauravi N. Trivedi $\mathbb{D}^{\text {, }}$ \\ Sureshkumar N. Mesara 1 and R.B. Subramanian*
}

Post Graduate Department of Biosciences, Centre of Advanced Study in Bioresource Technology, Sardar Patel University, Satellite Campus, Bakrol-Vadtal Road, Bakrol, Anand - 388 315, Gujarat, India.

\begin{abstract}
Rapidly spreading outbreak of the novel Severe Acute Respiratory Syndrome Coronavirus-2 (SARS-CoV-2) is causing serious health concerns worldwide. It started as an epidemic in Wuhan, Hubei province, central China, and has now become a pandemic, spreading over most of the continents of the planet. The major clinical symptoms of the infection are dry cough, fever, pneumonia, respiratory failure, hypoxia, and in certain cases, even death. Alveolar damage and respiratory system failure are observed in severe cases. Initial mild infection leads to activation of the immune system in the lungs and accumulation of various inflammatory cells and molecules. At a later phase during the infection, a "cytokine storm" causes an Acute Respiratory Distress Syndrome (ARDS), leading to an increase in the production of pro-inflammatory cytokines, migration of a large number of immune cells to the site of infection, and ultimately pulmonary damage. The rapid and uncontrolled outbreak requires putative therapeutic drugs for treatment of patients suffering from COVID-19. Amongst the currently used antiviral drugs, such as hydroxychloroquine, lopinavir, remdesivir etc. we would like to present an update on another effective drug, pentoxifylline. Pentoxifylline has anti-inflammatory, immunomodulatory, anti-viral, and bronchodilatory properties. Pentoxifylline is known to reduce cytokine production, immune cell migration, and suppress certain signal transduction pathways (e.g. NF-к $\beta$ and STAT3). Thus, it minimizes inflammatory damage in the lung tissues.
\end{abstract}

Keywords: Anti-inflammatory, Anti-viral, COVID-19, Cytokines, Pentoxifylline, SARS-CoV-2

*Correspondence: promat103vans@gmail.com,+91 9898538599

(Received: May 05, 2020; accepted: May 14, 2020)

Citation: Dhameliya HA, Thakkar VR, Trivedi GN, Mesara SN, Subramanian RB. Pentoxifylline: An Immunomodulatory Drug for the Treatment of COVID-19. J Pure Appl Microbiol. 2020;14(Spl Edn.):861-867. doi: 10.22207/JPAM.14.SPL1.23

(C) The Author(s) 2020. Open Access. This article is distributed under the terms of the Creative Commons Attribution 4.0 International License which permits unrestricted use, sharing, distribution, and reproduction in any medium, provided you give appropriate credit to the original author(s) and the source, provide a link to the Creative Commons license, and indicate if changes were made. 


\section{INTRODUCTION}

The recent outbreak of the novel Severe Acute Respiratory Syndrome Coronavirus-2 (SARSCoV-2) as Corona Virus Disease-2019 (COVID-19) is causing serious health concerns worldwide. COVID-19, which started as an epidemic (the rapid spread of disease to a large number of people within a community, population, or region) has now been declared as a pandemic (an epidemic that spreads over multiple countries or continents) by the World Health Organization. Since 12 December 2019, 2,774,135 laboratory cases have been confirmed including 190,871 deaths worldwide as reported on 26 April $2020^{1,2}$.

SARS-CoV- 2 belongs to the Betacoronavirus genera of the Coronaviridae family. SARS-CoV-2 is the third outbreak of the Betacoronavirus within the last two decades, including the SARS-CoV outbreak in 2003, and the MERS-CoV (Middle Eastern respiratory syndrome coronavirus) outbreak in 2012 $2^{3,4}$. Coronaviruses are enveloped, non-fragmented, single-stranded, and contain positive-sense RNA as their genetic material ${ }^{4}$. This virus can be easily transmitted from one person to another through droplets generated by coughing or sneezing, through personal contact, or by touching contaminated surfaces or equipments.

Several anti-viral drugs are proposed and tested for the treatment of COVID-19. Lopinavir, along with a booster dose of ritonavir, is a drug widely used for the treatment of HIV. Despite the treatment being beyond standard care, no positive effect was observed when the COVID-19 patients were treated with lopinavir-ritonavir ${ }^{5}$. Another popular drug remdesivir, which is a broad-spectrum antiviral drug, is able to inhibit viral replication of multiple genetically unrelated RNA viruses ${ }^{6}$. Although treatment with remdesivir leads to a significant reduction of the viral titer in the lungs, it failed to improve the pulmonary damage that occurred in the later stages of MERS, SARS, and COVID- $19^{7}$. Since SARS-CoV- 2 infection is driven by both the virus and the host immune response, use of only an anti-viral drug, such as remdesivir may not be able to restore pulmonary homeostasis. Currently, hydroxycholoroquine (an anti-malarial drug) has gained much attention for the treatment of COVID-19 patients due to its anti-viral and immunomodulatory properties ${ }^{8}$.
However, hydroxychloroquine is known for its relatively narrow therapeutic index, cardiac toxicity, prolonged QT (interval between ventricular depolarization and repolarization), and sodium channel inhibition, which results in ventricular arrhythmias, conduction blockade, and cardiovascular collapse ${ }^{9}$. Considering efficacies and limitations of the aforementioned drugs, some important features of pentoxifylline are highlighted in this review.

\section{COVID-19 and its Immunopathology}

COVID-19 with symptoms similar to pneumonia started in Wuhan, Hubei province, central China and has now spread to almost 213 countries $^{2}$. Typical clinical features of the patients infected with this virus include fever, fatigue, dry cough, nausea, chest tightness, dyspnoea (breathing difficulties), headache, pneumonia, and sometimes death ${ }^{2,10}$. Alveolar damage and respiratory system failure are the most severe pathologies of this disease. Lung autopsies of the patients suffering from SARS showed flooding of the alveolar lumina mixed with inflammatory cells, increased alveolar macrophage population, and hemophagocytosis ${ }^{11}$. A close resemblance has been found between the pathogenicity and the pattern of inflammatory damage caused by SARS-CoV and SARS-CoV-2.

The human airway epithelium is an important physical barrier against external pathogens and allergens. It also regulates pulmonary inflammation. SARS-CoV-2 infection induces interferon-stimulated genes that inhibit viral replication. As a response to the anti-viral activity of the host, the viral system encodes various antagonist molecules to modulate the interferon activity ${ }^{3}$. Epithelial cells produce various cytokines and chemokines in response to pathogens and generate inflammatory reactions associated with a variety of lung diseases. The cytokine network includes alveolar macrophages, eosinophils, mast cells, and T lymphocytes ${ }^{12}$. Biological effects of cytokines are dependent on their concentration. At a lower concentration, many cytokines regulate normal physiological processes while at higher concentrations, they mediate local or systemic inflammatory responses. At the highest concentration, cytokines exert adverse effects to the host causing tissue damage ${ }^{13}$. Increased levels of proinflammatory cytokines (e.g. interferon 
gamma (IFN $\gamma$ ), interleukin (IL)- 1 $\beta$, IL- 2, IL-6, IL-8, tumor necrosis factor alpha (TNF $\alpha$ ), IFN $\gamma$ induced protein-10 (IP10), macrophage inflammatory protein-1 (MIP1), granulocyte-colony stimulating factor (GCSF), and monocyte chemoattractant protein-1 (MCP1)) are responsible for pulmonary inflammation and extensive lung damage ${ }^{14,15}$. Expression of IL- 8 and MCP-1 by the pulmonary epithelial cells facilitate migration of inflammatory and activated cells to the target tissue ${ }^{16}$. Depletion of CD4+ and CD8+ T lymphocytes in the patients infected with SARS is also associated with the adverse outcomes of the disease ${ }^{15}$. Thus, two main features of the immune dysregulations generated by SARS-CoV-2 are: (a) overproduction of proinflammatory cytokines by monocytes at the site of the infection, and (b) dysregulation of lymphocytes such as CD4+ T-cells and CD8+ T-cells, and (Natural Killer) NK cell count depletion 17. Chronic inflammation, which occurs at a later phase of the disease, is the main cause of Acute Respiratory Distress Syndrome (ARDS). ARDS is a secondary clinical manifestation of the COVID-19 infection, caused by pneumonia and sepsis due to "cytokine storm", in which the immune and non-immune cells associated with inflammation release huge amounts of pro-inflammatory cytokines that cause damage to the host ${ }^{18}$.

Nuclear factor kappa-light-chainenhancer of activated $B$ cells (NF-K $\beta$ ) is an important ubiquitous transcription factor and a pleotropic regulator of many genes involved in inflammatory response and immunoregulatory activities $^{19}$. The major pathway that functions after the patient is infected with coronavirus is the activation of the NF- $\mathrm{K} \beta$ pathway through myeloid differentiation factor 88 (MyD88) leading to the induction of a variety of pro-inflammatory cytokines including IL- 6 and TNF- $\alpha^{20}$. IL-6 in turn activates signal transducer and activator of transcription 3 (STAT3), which is required for complete activation of the NF- $\beta \beta$ pathway. NF- $\beta \beta$ and STAT3 together activate the IL-6 amplifier leading to multiple inflammatory and autoimmune diseases $^{21}$. IL-6 induces various pro-inflammatory cytokines and recruits various inflammatory cells to the target tissues. IL-6 is an important marker of cellular senescence. The amount of cellular IL-6 amplifier increases with age, and this might be one of the possible reasons for age dependent mortality of COVID-19 18 .

Cytokines up-regulate the expression of leukocyte adhesion molecules such as intercellular adhesion molecule-1 (ICAM-1) on the epithelial and endothelial cells of the lung airway ${ }^{22}$. ICAM-1 in turn mediates binding of activated T lymphocytes to the alveolar epithelial cells and retains the activated T lymphocytes ${ }^{23}$. T lymphocyte derived cytokine, IFN- $\beta$, is known for its cytotoxic effects and it participates in pulmonary inflammation by inducing the expression of ICAM- 1 in the epithelial cells ${ }^{12}$.

Production and activity of the inflammatory cytokines at the site of infection may help the host by promoting the accumulation of polymorphonuclear leukocytes (PMNs) and activating their anti-pathogenic functions. However, prolonged and excessive activation of PMNs can initiate microvascular injury, resulting in increased vasopermeability, hemorrhage, and thrombosis ${ }^{13}$. It altogether causes fever, dry cough, and pneumonia in the COVID-19 patients.

Pentoxifylline

Pentoxifylline (Oxpentifylline) (Fig. 1 ) is a methylxanthine derivative, also known as 1-(5-Oxohexyl)-3,7-dimethylxanthine, 1-(5-Oxohexyl)-theobromine. Its pharmacological properties are similar to other known xanthines such as theobromine, caffeine, and theophylline ${ }^{24}$. It has anti-viral, immunomodulatory, antiinflammatory, and bronchodilator effects ${ }^{25-28}$. As a bronchodilator it reduces the thickness of blood, increases the red blood cell flexibility so they can migrate through narrow capillaries more rapidly and as a result eases blood circulation ${ }^{24}$. Pentoxifylline has a broad spectrum of antiviral activity, as it is used against almost eight viruses namely herpes simplex virus, vaccinia virus, rotavirus, tick-borne encephalitis virus,<smiles>CC(=O)CCCCn1c(=O)c2c(ncn2C)n(C)c1=O</smiles>

Fig. 1. Chemical structure of pentoxifylline 
Table 1. Summary of the action of pentoxifylline against clinical manifestations of SARS-CoV-2 in COVID-19 patients

\begin{tabular}{|c|c|}
\hline Clinical manifestations of COVID-19 & Effectiveness of pentoxifylline \\
\hline $\begin{array}{l}\text { Viral infection and proliferation in lung } \\
\text { tissues }\end{array}$ & $\begin{array}{l}\text { - Demonstrates anti-viral activity against } 8 \text { deadly viruses } \\
\text { and may effectively inhibit SARS-CoV- } 2 \text { replication }\end{array}$ \\
\hline $\begin{array}{l}\text { Production of TNF- } \alpha \text { and IL-1 by alveolar } \\
\text { macrophages }\end{array}$ & $\begin{array}{l}\text { - Inhibits production of TNF- } \alpha \text {, and IL-1 from macrophages } \\
\text { and other cells }\end{array}$ \\
\hline $\begin{array}{l}\text { Increased expression of surface ICAM-1 on } \\
\text { the lung epithelial and endothelial cells, } \\
\text { leading to binding of more T- cells }\end{array}$ & $\begin{array}{l}\text { - Reduces the expression of ICAM-1 and thus, decreases } \\
\text { binding of T- cells }\end{array}$ \\
\hline $\begin{array}{l}\text { Accumulation and prolonged activation of } \\
\text { PMNs leading to increased microvascular } \\
\text { injuries, hemorrhage, and thrombosis }\end{array}$ & $\begin{array}{l}\text { - Increases the cAMP levels in PMNs, thus decreasing } \\
\text { chemotaxis towards the inflammatory sites and results in } \\
\text { decreased microvascular injuries, hemorrhage, and } \\
\text { thrombosis }\end{array}$ \\
\hline $\begin{array}{l}\text { Expression of IL- } 8 \text { and MCP-1; increased } \\
\text { migration of other inflammatory cells to the } \\
\text { target tissue }\end{array}$ & $\begin{array}{l}\text { - Reduces production of IL- } 8 \text { and MCP- } 1 \text {; decreased migration } \\
\text { of inflammatory cells to the target tissue }\end{array}$ \\
\hline $\begin{array}{l}\text { Promotes signaling through STAT3 and NF- } \\
\mathrm{\kappa} \beta \text { for production of pro-inflammatory cytokines }\end{array}$ & $\begin{array}{l}\text { - Suppresses signaling through STAT3 and NF-K } \beta \text { leading to } \\
\text { decreased production of IL-6, TNF- } \alpha \text {, and other cytokines }\end{array}$ \\
\hline $\begin{array}{l}\text { Activates phosphodiesterase in various } \\
\text { immune and pro-inflammatory cells, leading } \\
\text { to production of cytokines }\end{array}$ & $\begin{array}{l}\text { - Inhibits phosphodiesterase and thus, decreases production } \\
\text { of pro-inflammatory cytokines }\end{array}$ \\
\hline
\end{tabular}

HIV, hepatitis JA virus, vesicular stomatitis virus, and West Nile virus ${ }^{26}$. The anti-inflammatory activity of pentoxifylline is associated with its ability to inhibit the production and/or function of proinflammatory cytokines ${ }^{28}$. Pentoxifylline is comparatively inexpensive and has fewer side effects compared to the other anti-inflammatory and anti-viral drugs ${ }^{29}$. It can be administered through oral or intravenous routes, and can be metabolized by the red blood cells and the liver. It has an elimination half-life of 3.4 hours $^{24}$. Moreover, research suggests that pentoxifylline can inhibit microvascular constriction, block red blood cell and platelet aggregation, decrease plasma fibrinogen levels, stimulate fibrinolysis, and suppress leukocyte deformability ${ }^{30,31}$.

Pentoxifylline is able to inhibit the actions of IL- 1 , TNF- $\alpha$, and TNF- $\beta$, reduce ICAM- 1 expression, and reduce IL- 8 and $\mathrm{MCP}-1$ production in vivo ${ }^{12,29}$. Dose-dependent pentoxifylline induced suppression of TNF- $\alpha$ has been observed in human trials and inhibition of spontaneous production of TNF- $\alpha$ was also demonstrated in early studies ${ }^{29}$. Blockage of adhesion molecules and chemotactic activities can reduce migration of inflammatory cells in the lung airway and present potent and possible targets for future anti-inflammatory therapies in airway diseases ${ }^{12}$. Pentoxifylline as a phosphodiesterase inhibitor raises cyclic AMP (CAMP) levels in PMNs, resulting in decreased PMN chemotaxis towards the site of inflammation and thus, reduced microvascular injury, vasopermeability, hemorrhage, and thrombosis ${ }^{13,32,33}$.

Pentoxifylline is non-specific inhibitor of phosphodiesterase (PDE) ${ }^{19}$. PDE is present in almost every pro-inflammatory and immune cell and it regulates the metabolism of CAMP ${ }^{26}$. However, a specific type of PDE isoenzyme regulates only a specific type of inflammatory cytokine biosynthesis ${ }^{34}$. Since lung tissues consist of a variety of PDE isoenzymes (I, II, III, V, and VII) and the isoenzymes that are activated by the coronavirus infection are unknown, the use of non-specific inhibitor, preferably pentoxifylline could have a broader range of inhibitory activity in SARS-CoV- ${ }^{19}$.

Two different studies conducted on invitro cultured smooth muscle cells (SMC) have shown the inhibitory action of pentoxifylline on the activity of NF-K $\beta^{35,36}$. Inhibition of NF-K $\beta$ activity may down-regulate production and secretion of IL- 6 and TNF- $\alpha$. Experiments on A375 human melanoma cell-line and A549 lung cancer cellline have shown dose-dependent suppressed phosphorylation and DNA binding of STAT3, as well as limited secretion of IL- $6^{37,38}$. 


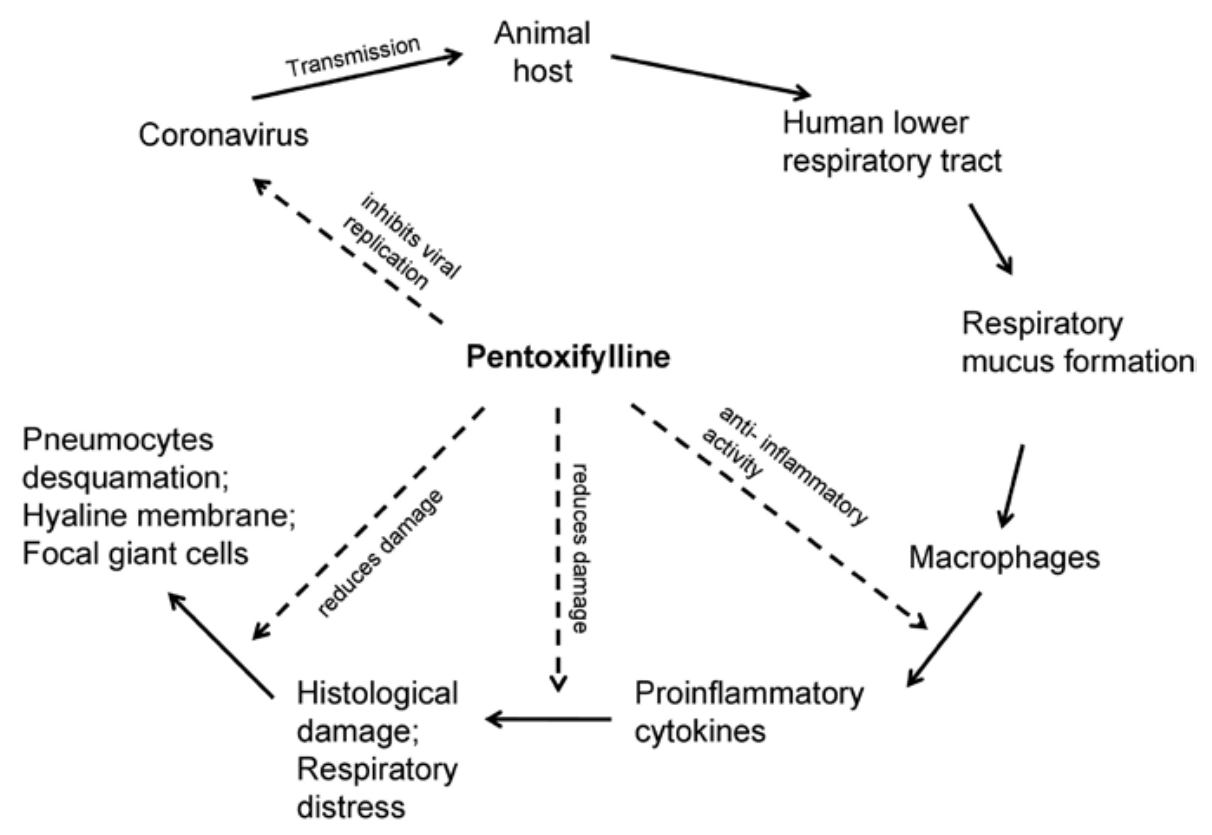

Fig. 2. Coronavirus cycle and the hypothetical activity of pentoxifylline

Moreover, pentoxifylline has a very low toxicity level and has minimal side effects. However, its long-term use may cause dizziness, headache, nausea, or stomach discomfort in some patients ${ }^{26}$. It is highly advisable to take this drug only as prescribed by the physician.

\section{DISCUSSION}

COVID-19 is a life-threatening disease that has spread worldwide and infected millions of people within a short period of time. With an average reproduction number of $3.28\left(R_{0}\right.$, an indication of transmissibility of a virus, representing the average number of new infections generated by a single infectious person in a totally naive population), novel SARS-CoV-2 is rapidly spreading in all the countries of the world ${ }^{39}$. Almost all of the SARS-CoV-2 patients with pneumonia, who develop severe respiratory failure, are diagnosed with hyper-inflammatory response, increased pro-inflammatory cytokine production, and dysregulation of lymphocytes. Moreover, severe consequences of the disease are diffused alveolar damage, hyaline membrane formation, inflammation in the alveolar walls, desquamation of pneumocytes, and patients also develop secondary bacterial pneumonia in case of further complications ${ }^{4}$. Large amounts of proinflammatory cytokines released by the alveolar macrophages and other activated cells have a prominent role in the pathology of SARS ${ }^{11}$. The above mentioned clinical manifestations suggest the use of immunomodulatory drugs for treatment of patients suffering from COVID-19.

Anti-inflammatory, immunomodulatory, anti-viral, and bronchodilatory properties of pentoxifylline makes it the most suitable drug for the treatment of COVID-19. Pentoxifylline may have a possible anti-viral activity against SARSCoV-2, along with a cytokine-modulation activity, but not as immunosuppressant as observed in the case of corticoids. It down-regulates only the cytokine activity and leaves the rest of immune response functional. It is an inexpensive drug, has a very low cytotoxicity, and has minimal side effects. Safe use of pentoxifylline has been shown in a number of clinical trials. Thus, all the characteristics of pentoxifylline make it a promising and efficient therapeutic drug to treat patients suffering from COVID-19. However, clinical trials and approvals are required before incorporating pentoxifylline as a routine treatment of COVID-19. 


\section{CONCLUSION}

Neither vaccines nor precise pharmaceutical medicines for treatment of COVID-19 are formulated till date. The recent strategy to be considered is to study the properties and effectiveness of available pharmacological medicines and to use one or a combination of two or more drugs to overcome the manifestations of the disease. Existing evidences strongly support an important role of abnormal immune response in the pathogenesis of SARS-CoV- 2 . Thus, immunomodulatory drugs could be a better alternative along with an antiviral therapy. The immunomodulatory drug pentoxifylline is inexpensive and has no defined adverse effects. Thus, it can be an effective therapeutic agent. However, clinical experiments are yet to be performed to study the effects of pentoxifylline on COVID-19 patients.

\section{ACKNOWLEDGEMENTS}

None.

\section{CONFLICT OF INTEREST}

The authors declares that there is no conflict of interest.

\section{AUTHORS' CONTRIBUTION}

All the listed author(s) have made a substantial, direct and intellectual contribution to the work, and approved it for publication.

\section{FUNDING}

None.

\section{ETHICS STATEMENT}

This article does not contain any studies with human participants or animals performed by any of the authors.

\section{DATA AVAILABILITY}

All datasets generated or analyzed during this study are included in the manuscript and/or the Supplementary Files.

\section{REFERENCES}

1. Coronavirus disease 2019. https://www.who.int/ emergencies/diseases/novel-coronavirus-2019. Accessed April 26, 2020.

2. Zhou P, Yang X-L, Wang X-G, et al. A pneumonia outbreak associated with a new coronavirus of probable bat origin. Nature. 2020;579(7798):270-273 . https://doi.org/10.1038/s41586-020-2012-7

3. Harapan $\mathrm{H}$, Itoh $\mathrm{N}$, Yufika $\mathrm{A}$, et al. Coronavirus disease 2019 (COVID-19): A literature review. J Infect Public Health. 2020;13(5):667-673. https://doi. org/10.1016/j.jiph.2020.03.019

4. Guarner J. Three Emerging Coronaviruses in Two Decades. Am J Clin Pathol. 2020;153(4):420-421. https://doi.org/10.1093/ajcp/aqaa029

5. Cheng C-Y, Lee Y-L, Chen C-P, et al. Lopinavir/ritonavir did not shorten the duration of SARS CoV-2 shedding in patients with mild pneumonia in Taiwan. J Microbiol Immunol Infect, 2020. https://doi.org/10.1016/j. jmii.2020.03.032

6. Sheahan TP, Sims AC, Graham RL, et al. Broad-spectrum antiviral GS-5734 inhibits both epidemic and zoonotic coronaviruses. Sci Trans/ Med. 2017;9(396): https:// doi.org/10.1126/scitrans/med.aal3653

7. Sheahan TP, Sims AC, Leist SR, et al. Comparative therapeutic efficacy of remdesivir and combination lopinavir, ritonavir, and interferon beta against MERSCoV. Nat Commun. 2020;11(1):1-14. https://doi. org/10.1038/s41467-019-13940-6

8. Singh AK, Singh A, Shaikh A, Singh R, Misra A. Chloroquine and hydroxychloroquine in the treatment of COVID-19 with or without diabetes: A systematic search and a narrative review with a special reference to India and other developing countries. Diabetes Metab Syndr Clin Res Rev. 2020;14(3):241-246. https:// doi.org/10.1016/j.dsx.2020.03.011

9. Megarbane B. Chloroquine and hydroxychloroquine to treat COVID-19: between hope and caution. Clin Toxicol (Phila). 2020. https://doi.org/10.1080/15563 650.2020.1748194

10. Dong X, Cao Y, Lu X, et al. Eleven Faces of Coronavirus Disease 2019. Allergy. 2020. https://doi.org/10.1111/ all.14289

11. Nicholls JM, Poon LL, Lee KC, et al. Lung pathology of fatal severe acute respiratory syndrome. Lancet. 2003;361(9371):1773-1778. https://doi.org/10.1016/ S0140-6736(03)13413-7

12. Krakauer T. Pentoxifylline inhibits ICAM-1 expression and chemokine production induced by proinflammatory cytokines in human pulmonary epithelial cells. Immunopharmacology. 2000;46(3):253-261. https:// doi.org/10.1016/S0162-3109(99)00186-1

13. Sullivan GW, Carper HT, Novick WJ, Mandell GL. Inhibition of the inflammatory action of interleukin-1 and tumor necrosis factor (alpha) on neutrophil function by pentoxifylline. Infect Immun. 1988;56(7):1722-1729. https://doi.org/10.1128/ IAI.56.7.1722-1729.1988

14. Huang C, Wang Y, Li X, et al. Clinical features of patients infected with 2019 novel coronavirus in Wuhan, China. Lancet. 2020;395(10223):497-506. https://doi. org/10.1016/S0140-6736(20)30183-5

15. Wong RSM, Wu A, To KF, et al. Haematological manifestations in patients with severe acute respiratory syndrome: retrospective analysis. $B M J$. 2003;326(7403):1358-1362. https://doi.org/10.1136/ bmj.326.7403.1358

16. Kunkel SL, Strieter RM. Cytokine Networking in Lung 
Inflammation. Hosp Pract. 1990;25(10):63-76. https:// doi.org/10.1080/21548331.1990.11704020

17. Giamarellos-Bourboulis EJ, Netea MG, Rovina N, et al. Complex Immune Dysregulation in COVID-19 Patients with Severe Respiratory Failure. Cell Host Microbe. April 2020. https://doi.org/10.1016/j. chom.2020.04.009

18. Hirano T, Murakami M. COVID-19: A New Virus, but a Familiar Receptor and Cytokine Release Syndrome. Immunity. 2020. https://doi.org/10.1016/j. immuni.2020.04.003

19. Bermejo JF, Munoz-Fernandez MA. Severe Acute Respiratory Syndrome, a Pathological Immune Response to the New Coronavirus-Implications for Understanding of Pathogenesis, Therapy, Design of Vaccines, and Epidemiology. Viral Immunol. 2004;17(4):535-544. https://doi.org/10.1089/ vim.2004.17.535

20. de Wit E, van Doremalen N, Falzarano D, Munster VJ. SARS and MERS: recent insights into emerging coronaviruses. Nat Rev Microbiol. 2016;14(8):523-534. https://doi.org/10.1038/nrmicro.2016.81

21. Murakami M, Kamimura D, Hirano T. Pleiotropy and Specificity: Insights from the Interleukin 6 Family of Cytokines. Immunity. 2019;50(4):812-831. https://doi. org/10.1016/j.immuni.2019.03.027

22. Krakauer T, Stiles BG. Pentoxifylline Inhibits Superantigen-Induced Toxic Shock and Cytokine Release. Clin Diagnostic Lab Immunol. 1999;6(4):594598. https://doi.org/10.1128/CDLI.6.4.594-598.1999

23. Christensen PJ, Kim S, Simon RH, Toews GB, Paine R. Differentiation-related Expression of ICAM-1 by Rat Alveolar Epithelial Cells. Am J Respir Cell Mol Biol. 1993;8(1):9-15. https://doi.org/10.1165/ajrcmb/8.1.9

24. Samlaska CP, Winfield EA. Pentoxifylline. J Am Acad Dermatol. 1994;30(4):603-621. https://doi. org/10.1016/S0190-9622(94)70069-9

25. Fujimoto $\mathrm{T}$, Nakamura $\mathrm{T}$, Furuya $\mathrm{T}$, et al. Relationship between the Clinical Efficacy of Pentoxifylline Treatment and Elevation of Serum T Helper Type 2 Cytokine Levels in Patients with Human T-lymphotropic Virus Type I-Associated Myelopathy. Intern Med. 1999;38(9):717-721. https://doi.org/10.2169/ internalmedicine.38.717

26. Bermejo Martin JF, Jimenez JL, Munoz-Fernandez A. Pentoxifylline and severe acute respiratory syndrome (SARS): a drug to be considered. Med Sci Monit. 2003;9(6):SR29-34. http://www.ncbi.nlm.nih.gov/ pubmed/12824965

27. Navarro J, Punzon C, Jimenez JL, et al. Inhibition of Phosphodiesterase Type IV Suppresses Human Immunodeficiency Virus Type 1 Replication and Cytokine Production in Primary T Cells: Involvement of NF-KB and NFAT. J Virol. 1998;72(6):4712-4720. https:// doi.org/10.1128/JVI.72.6.4712-4720.1998

28. Navarro J, Punzon MC, Pizarro A, Fernandez-Cruz E, Fresno M, Munoz-Fernandez MA. Pentoxifylline inhibits acute HIV-1 replication in human T cells by a mechanism not involving inhibition of tumour necrosis factor synthesis or nuclear factor-kB activation. AIDS. 1996;10(5):469-475. https://doi. org/10.1097/00002030-199605000-00004

29. Marques LJ, Zheng L, Poulakis N, Guzman J, Costabel U. Pentoxifylline Inhibits TNF- $\alpha$ Production from Human Alveolar Macrophages. Am J Respir Crit Care Med. 1999;159(2):508-511. https://doi.org/10.1164/ ajrccm.159.2.9804085

30. Ely H. Pentoxifylline Therapy in Dermatology: A Review of Localized Hyperviscosity and Its Effects on the Skin. Dermatol Clin. 1988;6(4):585-608. https://doi. org/10.1016/S0733-8635(18)30637-5

31. Ward A, Clissold SP. Pentoxifylline. Drugs. 1987;34(1):50-97. https://doi.org/10.2165/00003495198734010-00003

32. Bessler H, Gilgal R, Djaldetti M, Zahavi I. Effect of Pentoxifylline on the Phagocytic Activity, cAMP Levels, and Superoxide Anion Production by Monocytes and Polymorphonuclear Cells. J Leukoc Biol. 1986;40(6):747-754. https://doi.org/10.1002/ jlb.40.6.747

33. Hill HR, Augustine NH, Newton JA, Shigeoka AO, Morris $E$, Sacchi F. Correction of a developmental defect in neutrophil activation and movement. Am J Pathol. 1987;128(2):307-314.

34. Haddad JJ, Land SC, Tarnow-Mordi WO, Zembala M, Kowalczyk D, Lauterbach R. Immunopharmacological Potential of Selective Phosphodiesterase Inhibition. I. Differential Regulation of LipopolysaccharideMediated Proinflammatory Cytokine (Interleukin-6 and Tumor Necrosis Factor- $\alpha$ ) Biosynthesis in Alveolar Epithelial Cells.J Pharmacol Exp Ther. 2002;300(2):559566. https://doi.org/10.1124/jpet.300.2.559

35. Bellas RE, Lee JS, Sonenshein GE. Expression of a constitutive NF-kappa B-like activity is essential for proliferation of cultured bovine vascular smooth muscle cells. J Clin Invest. 1995;96(5):2521-2527. https://doi.org/10.1172/JCl118313

36. Bretschneider E, Wittpoth $M$, Weber AA, Glusa E, Schror K. Activation of NFKB is essential but not sufficient to stimulate mitogenesis of vascular smooth muscle cells. Biochem Biophys Res Commun. 1997;235(2):365-368. https://doi.org/10.1006/ bbrc.1997.6788

37. Kamran MZ, Gude RP. Pentoxifylline inhibits melanoma tumor growth and angiogenesis by targeting STAT3 signaling pathway. Biomed Pharmacother. 2013;67(5):399-405. https://doi.org/10.1016/j. biopha.2013.03.020

38. Kamran MZ, Patil P, Gude RP. Role of STAT3 in Cancer Metastasis and Translational Advances. Biomed Res Int. 2013; 2013:1-15. https://doi. org/10.1155/2013/421821

39. Liu Y, Gayle AA, Wilder-Smith A, Rocklov J. The reproductive number of COVID-19 is higher compared to SARS coronavirus. J Travel Med. 2020;27(2):https:// doi.org/10.1093/jtm/taaa021 